\title{
EMPREENDEDORISMO POPULAR E ASCENSÃO SOCIAL EM DIFERENTES CONTEXTOS URBANO-REGIONAIS: UMA ANÁLISE PRELIMINAR EM DOIS BAIRROS POPULARES DA BAHIA
}

\author{
ANGELO SERPA ${ }^{1}$ \\ Universidade Federal da Bahia
}

\begin{abstract}
Resumo: Neste artigo são apresentados os fundamentos da pesquisa Empreendedorismo popular e ascensão social em diferentes contextos urbano-regionais e os primeiros resultados de dois estudos de caso: no bairro Tomba - em Feira de Santana (território do Portal do Sertão) - e no bairro Paripe, em Salvador (território Metropolitano). Parte-se da análise de um fenômeno novo, que vem se manifestando nos bairros populares das cidades brasileiras, que apresentam cada vez mais moradores com renda mais elevada e em processo de "ascensão social" relativa. Tais áreas vêm se tornando mais complexas e autossuficientes, com a multiplicação de subcentros (e sua diversificação). Foram catalogados e mapeados os estabelecimentos comerciais e de serviços localizados no Tomba e em Paripe, assim como aplicados questionários junto aos consumidores e empreendedores visando delinear seu perfil nos núcleos comerciais e de serviços mais significativos. Com a caracterização dos empreendimentos e do perfil de consumidores e empreendedores, iniciaram-se as entrevistas com empreendedores amostrados entre aqueles que responderam aos questionários na primeira fase da pesquisa, de modo a caracterizá-los quanto à sua posição e sua condição na estrutura social, enfatizando suas trajetórias e seu capital (social, cultural e econômico). Essas entrevistas permitiram inferir que a ascensão na estrutura social dos entrevistados implica o endividamento e o empobrecimento do capital social que dispõem. O capital escolar/cultural permanece praticamente inalterado - a continuidade dos estudos dependendo de um enorme esforço pessoal daqueles que se dispõem a fazê-lo. São fortes os indícios de que esta ascensão se dá mais pela inserção no consumo do que por um incremento dos anos de escolaridade ou por participação em eventos e manifestações
\end{abstract}

\footnotetext{
${ }^{1}$ Professor titular de Geografia Humana da UFBA, pesquisador 1B CNPq. Contato: angserpa@ufba.br.
} 
culturais. Por outro lado, percebe-se também que esta inserção pode interferir nas relações sociais dos bairros populares analisados - com o empobrecimento do capital social de empreendedores (e consumidores), em suas trajetórias ascendentes na estrutura social das cidades e regiões onde atuam, com consequências, portanto, na estrutura social dos bairros como um todo.

Palavras-chave: Empreendedorismo Popular; Ascensão Social; Bairros Populares; Comércio e Serviços; Bahia.

\section{POPULAR ENTREPRENEURSHIP AND UPWARD SOCIAL MOBILITY IN DIFFERENT URBAN AND REGIONAL CONTEXTS: A PRELIMINARY ANALYSIS OF TWO POPULAR NEIGHBORHOODS IN BAHIA}

Abstract: This article presents the foundations of the research "Popular entrepreneurship and upward social mobility indifferent urban and regional contexts" and the first results of two case studies: the neighborhood of Tomba, in Feira de Santana (territory of Portal do Sertão), and the neighborhood of Paripe, in Salvador (Metropolitan territory). It starts with the analysis of a new phenomenon, which has been manifesting itself in popular neighborhoods of Brazilian cities that increasingly accommodate residents with higher income and in the process of relative "upward social mobility". These areas are becoming more complex and self-sufficient, with the multiplication of sub-centers (and their diversification). The commercial and service establishments located on Tomba and Paripe were classified and mapped. In addition, questionnaires were carried out with consumers and entrepreneurs in the most important commercial and service centers with the aim of outlining their profile. After characterizing the shopping centers, as well as outlining the profile of consumers and entrepreneurs, we conducted interviews with the entrepreneur sampled in the first phase of the research, in order to characterize their position and their status in the social structure, emphasizing their trajectories and their capital (social, economic and cultural). These interviews allowed us to infer that the respondents' upward mobility in the social structure was obtained through indebtedness and through the depletion of the social capital they have. The school/cultural capital remains virtually unchanged, the continuity of education depending on an enormous personal effort of those who are willing to do so. There is strong evidence that this mobility results more in better access to consumption than in an increase in years of schooling or in participation in cultural manifestations or events. On the other hand, it is also noted that social inclusion through consumption can interfere in the social relations of the popular neighborhoods analyzed, with the impoverishment of the social capital of entrepreneurs (and consumers) in their upward trajectories in the social structure of cities and regions where they operate, which has consequences, thus, to the social structure of the districts as a whole.

Keywords: Popular Entrepreneurship; Upward Social Mobility; Neighborhoods; Retailand Services; Bahia.

\section{Introdução}

Neste artigo apresentamos as premissas e os fundamentos da pesquisa Empreendedorismo Popular e Ascensão Social em Diferentes Contextos UrbanoRegionais: Uma análise socioespacial de trajetórias de indivíduos e grupos em bairros populares de cidades e regiões do Estado da Bahia, que vimos desenvolvendo em três distintas regiões (territórios de identidade) do Estado da 
Bahia, desde 2014, com o apoio do $\mathrm{CNPq}^{2}$. Pretende-se também apresentar e discutir os primeiros resultados dos levantamentos de campo em dois bairros populares: o bairro Tomba, em Feira de Santana (território do Portal do Sertão), e o bairroParipe, em Salvador (território Metropolitano). Esses levantamentos dão continuidade às pesquisas anteriores desenvolvidas no âmbito das atividades dos grupos de pesquisa Espaço Livre de Pesquisa-Ação e Territórios da Cultura Popular, do Departamento de Geografia da Universidade Federal da Bahia - em especial àquelas que trataram:a) da produção espacial do comércio e dos serviços nos bairros populares a partir de estudos de caso em Salvador-Bahia (SERPA, 2001);b) da percepção da identidade dos bairros populares estudados na capital baiana a partir das noções de intersubjetividade e de transubjetividade das imagens e representações, entendendo o "bairro" como um espaço social - reflexo e condição do/para o surgimento de um sistema de relações (SERPA, 2007a; 2007b);c) das identidades regionais e das políticas de desenvolvimento cultural e territorial aplicadas às diferentes regiões a partir de uma nova regionalização do Estado da Bahia em territórios de identidade, no ano de 2007 (SERPA, 2011; 2015).

Embora nossas pesquisas realizadas nos bairros populares de Salvador já indicassem, na segunda metade dos anos 1990, presença de população com renda familiar acima de cinco salários mínimos nas áreas de melhor infraestrutura e com maior oferta de bens e serviços, deve-se reconhecer que houve, de modo geral, um incremento de renda aos habitantes dos bairros populares das cidades a partir da intensificação dos programas de redistribuição de renda no país nos anos 2000.

Nos novos levantamentos iniciados em 2014, partimos da premissa de que as políticas de desenvolvimento territorial e cultural, assim como as que analisamos nos últimos anos em curso na Bahia, devem se nortear também por estas transformações do perfil de renda nas áreas populares dos respectivos territórios de identidade - que acrescentam novas variáveis e dimensões de análise à discussão das identidades espaciais (urbanas e regionais). Acrescente-se à ação do governo da Bahia e, em especial, da Secretaria de Cultura estadual, também outros programas do Ministério da Cultura (MinC), como os Pontos de Cultura ${ }^{3}$, o Mais

\footnotetext{
${ }^{2}$ Pretende-se realizar, no período de quatro anos, levantamentos de campo em pelo menos dois bairros populares de cada uma das três cidades propostas como recorte: Salvador (Território Metropolitano), Feira de Santana (Território do Portal do Sertão) e Vitória da Conquista (Território de Vitória da Conquista).

${ }^{3}$ O Programa Nacional de Cultura, Educação e Cidadania - Cultura Viva nasceu em 2004, criado pelo Ministério da Cultura (MinC) e regulamentado pelas Portarias MinC $\mathrm{n}^{\circ} 156$ e $\mathrm{n}^{\circ}$ 82, de 06 de julho de 2004 e 18 de maio de 2005, respectivamente. É executado pela Secretaria de Cidadania Cultural (SCC) que, até 2008, se chamava Secretaria de Programas e Projetos Culturais. Segundo Rocha (2010), ele foi criado como intuito de estimular e fortalecer no corpo do país uma rede de criação e
} 
Cultura $^{4}$ e o Vale Cultura ${ }^{5}$ - que podem estar contribuindo para a maior dinamização em termos culturais nos bairros populares das cidades brasileiras e que deveriam também se nortear pelos dados de incremento de renda da população dos bairros populares em seus respectivos contextos.

\section{Cercando o problema: classe $C$ e empreendedorismo popular}

\section{Dados da Secretaria de Assuntos Estratégicos do Governo Federal (SAE)} indicam que, na primeira década dos anos 2000, 25 milhões de pessoas passaram a integrar a chamada classe $C$, constituída de famílias com renda mensal per capita entre R \$ 291 e R \$ 1.019. 15 milhões de novos postos de trabalho foram criados no mesmo período. Pressupõe-se, a partir destas estatísticas oficiais, que cresceu também o potencial de consumo desse considerável contingente populacional (ver www.sae.gov.br).

Esses dados demonstram, porém, um foco exclusivo na renda - como destacado na citação abaixo extraída da publicação Vozes da Classe Média, da SAE - algo

gestão cultural (ver http://www.cultura.gov.br/culturaviva/cultura-viva/). Os Pontos de Cultura, base do Programa Cultura Viva, são instituições criadas a partir de iniciativas organizadas pela sociedade civil (ROCHA, 2010, p. 4).

${ }^{4}$ Lançado em outubro de 2007, o programa Mais Cultura, segundo o MinC, "representa o reconhecimento da cultura como necessidade básica, direito de todos os brasileiros, tanto quanto a alimentação, a saúde, a moradia, a educação e o voto. Com a criação do Programa, o Governo Federal incorpora a cultura como vetor importante para o desenvolvimento do país, incluindo-a na agenda social - com status de política estratégica de estado para atuar na redução da pobreza e da desigualdade social (...) Podem participar municípios, estados, pessoas físicas ou pessoas jurídicas de direito público ou privado, sem fins lucrativos, que sejam de natureza cultural, como associações, sindicatos, cooperativas, fundações, escolas caracterizadas como comunitárias e suas associações de pais e mestres, ou organizações tituladas como organizações da sociedade civil de interesse público (Oscips) e organizações sociais (OS), com atuação comprovada na área cultural há pelo menos dois anos" (http://www.cultura.gov.br/mais-cultura).

${ }^{5 “} \mathrm{O}$ Vale-Cultura é um benefício que será destinado prioritariamente a todos os trabalhadores que ganham até cinco salários mínimos. O objetivo é garantir meios de acesso e participação nas diversas atividades culturais desenvolvidas no Brasil. É parecido com o vale-transporte ou o vale-refeição. O trabalhador receberá um cartão magnético, complementar ao salário, que poderá usar para entrar em teatros, cinemas, comprar livros, CDs e consumir outros produtos culturais. O vale mensal será de R\$ 50. Os empregadores também são beneficiados com o vale. As empresas cadastradas no Programa de Cultura do Trabalhador recebem um incentivo fiscal do governo, podendo deduzir o valor despendido com o Vale-Cultura do imposto sobre a renda. A empresa pode descontar apenas $10 \%$ do valor do Vale-Cultura (R\$ 5,00) do salário, na forma que será definida em regulamento. O trabalhador também pode optar por não querer receber o benefício, caso deseje" (http://www.brasil.gov.br/sobre/cultura/iniciativas/vale-cultura). 
que será mais à frente aprofundado neste artigo e que leva a certa confusão sobre o que de fato pode ser considerado como classe média no Brasil:

No Brasil, esses limites de renda em valores monetários atuais são $\mathrm{R} \$ 291$ e $\mathrm{R} \$ 1.019$ por cada pessoa da família ao mês. Isso significa que são considerados membros da classe baixa aqueles com renda familiar per capita inferior a $\mathrm{R} \$ 291$ ao mês; pertencem à classe média os que apresentam renda familiar per capita entre $\mathrm{R} \$ 291$ e $\mathrm{R} \$ 1.019$; e acima de $\mathrm{R} \$ 1.019$, à classe alta. De acordo com essa classificação, hoje, $28 \%$ da população brasileira pertence à classe baixa; $52 \%$, à classe média e $20 \%$, à classe alta (SAE, 2012, p. 11).

Ou seja, pode-se inferir que a expressão classe $C$ é, para sistematização e divulgação dos dados oficiais, tida como homônima de classe média. De qualquer modo, é importante observar também neste documento, como era de se esperar, que, embora os dados oficiais indiquem que ter havido melhoras no campo brasileiro $^{6}$, a maior parte da classe $\mathrm{C}$ está concentrada nas cidades. Por outro lado, percebe-se que esta propalada ascensão em termos de renda não significou, pelo menos até aqui, melhora no nível de escolaridade da chamada nova classe C (ou classe média), como indica a mesma publicação:

$\mathrm{O}$ contingente de pessoas com ensino fundamental incompleto ou sem escolaridade que pertenciam à classe média era, em 2002, inferior ao contingente de brasileiros que pertenciam à classe média naquele ano (34\% contra 38\%). Já em 2012, após uma expansão líquida de 19 pontos percentuais, o contingente de pessoas com esse nível educacional que pertencem à classe média chega a $54 \%$, acima da proporção de brasileiros que pertencem a essa classe (52\% do total) (SAE, 2012, p. 28).

Embora o sentido desse aumento de renda entre aqueles com baixa escolaridade seja apresentado como algo positivo (o que é compreensível, já que se trata de uma publicação oficial), deve-se questionar considerar classe social como classe de renda de modo estrito, já que tal perspectivaparece ocultar mais do que revelarsobre os processos sociais, econômicos e culturais em jogo neste contexto de ascensão social, que é relativa. Os dados indicam, ainda, que aumentou a participação dos trabalhadores formais e também dos informais como integrantes

\footnotetext{
6“A proporção de pessoas na área rural que pertenciam à classe baixa, média e alta em 2002 eram, respectivamente, de $77 \%$, 21\% e $2 \%$, e, em 2012, correspondem a 52\%, 42\% e 6\%" (SAE, 2012, p. 28).
} 
da classe $\mathrm{C}^{7}$. O setor terciário (comércio e serviços) foi aquele que mais contribuiu para a ascensão social dos "entrantes da classe média" (SAE, 2012, p. 29).

Sabemos, no entanto, que o aumento de renda não está necessariamente atrelado a uma ascensão em termos de classe social, pois podemos afirmar, no caso brasileiro, que não se trata de uma emancipação pela escolaridade, mas, sim, pelo consumo. E o aumento de consumo, por outro lado, é condicionado também por maiores facilidades de crédito (o que provoca o endividamento) e políticas sociais de redistribuição de renda nos últimos anos no país.

Diante desse quadro, um fenômeno novo vem se manifestando nos bairros de perfil popular das cidades brasileiras, já que estes apresentam cada vez mais habitantes com renda mais elevada que, mesmo considerados em processo de "ascensão social", preferem continuar residindo nestas áreas. Desse modo, tais espaços vêm se tornando mais complexos e autossuficientes em termos de comércio e serviços, com a multiplicação de subcentros (e sua diversificação) nestes bairros populares das cidades brasileiras.

Embora possa se argumentar que o aumento da renda ainda não seja suficiente para que tais moradores possam mudar para outros bairros mais valorizados, há um contingente de habitantes que, mesmo com condições objetivas para a mudança, alegam razões subjetivas para a permanência, como "a falta de calor humano" nas chamadas áreas "nobres", "a tranquilidade" e o "ar de cidade do interior", ou ainda, raízes construídas ao longo de anos nos bairros populares das cidades (TOURINHO, 2013, p. A-6).

Sabe-se, também, que os bairros populares - em geral populosos e com grande extensão territorial - concentram uma boa parte dos pequenos negócios das cidades brasileiras. Embora não disponha de pesquisas de cunho estatístico, o Serviço Brasileiro de Apoio às Micro e Pequenas Empresas (SEBRAE) fez um levantamento dos empreendimentos por bairro para elaboração do roteiro Negócio a Negócio, no qual, em Salvador, são classificados como bairros empreendedores: Brotas, Cabula, Cajazeiras, Itapuã, Itapagipe, Liberdade, Pau Miúdo, Pau da Lima, Paripe e Pernambués.

\footnotetext{
7“"De cada 100 trabalhadores que entraram na classe média, 69\% ocupavam postos formais, o que elevou a contribuição dos trabalhadores formais para a classe média de 52\%, em 2002, para 58\%, em 2012. Já a proporção dos trabalhadores formais que pertencem à classe média passou de $51 \%$, em 2002, para 57\%, em 2012, enquanto que, dentre a população em idade ativa no Brasil, o contingente que pertencia à classe média representava apenas 41\%, em 2002 e, em 2012, representava 53\%. Isso revela uma forte representação da classe média entre os trabalhadores formais. Há que se ressaltar, também, que não foram apenas os trabalhadores formais que se beneficiaram do crescimento recente do país. Em 2002, 38\% dos trabalhadores informais pertenciam à classe média e, após uma expansão líquida de 15 pontos percentuais, $52 \%$ dos trabalhadores informais já pertencem a essa classe" (SAE, 2012, p. 28).
} 
Conforme a Associação Brasileira de Franchising, o crescimento dos pequenos negócios nos anos 2000 relaciona-se com a ascensão de mais indivíduos à classe $\mathrm{C}$, que utilizam recursos próprios para iniciar os novos empreendimentos (BORGES, 2013, p. 1-3). O SEBRAE vem, inclusive, desenvolvendo mutirões itinerantes de "empreendedorismo individual" em bairros populares das cidades baianas, a exemplo de Feira de Santana, no Portal do Sertão, onde o mutirão chegou aos bairros Feira 9 e Morada das Árvores (ver www.ba.agenciasebrae.com.br/). Em Vitória da Conquista, bairros como o Alto Maron $^{8}$ e o Patagônia também receberam os mutirões do SEBRAE.

Abre-se, aqui, um breve parêntese para afirmar que o sentido de empreendedorismo popular que embasa este artigo guarda poucas semelhanças com o conceito de empreendedorismo urbano nos moldes como vem sendo analisado na literatura especializada, particularmente nas áreas de planejamento e Geografia. O conceito de empreendedorismo urbano está relacionado aos modelos de planejamento estratégico e de urbanismo empresarial e concerne às ações de parceria dos poderes públicos e da iniciativa privada, visando à inserção competitiva de cidades na lógica da produção de mais valias relativas nos contextos nacionais e internacional, sob moldes como analisado por Compans (2005) ou Harvey (2005). O sentido de empreendedorismo popular defendido aqui é outro, já que diz respeito à criatividade de indivíduos e grupos em processo de ascensão social nos bairros populares em diferentes contextos urbano-regionais, criatividade esta expressa e condicionada pela complexificação de centralidades de comércio e serviços e, de modo mais geral, pelos campos da produção e do consumo (incluindo os culturais) - ideias que também serão aprofundadas mais adiante.

Assim, pode-se supor uma complexificação dos campos da produção e do consumo nos bairros populares das cidades em diferentes contextos urbanoregionais, o que nos faz pensar nas trajetórias de indivíduos e grupos na estrutura social, com relações diretas na produção do espaço urbano e regional. Isso inclui também a necessidade de se refletir sobre os impactos nos campos específicos da produção e do consumo culturais e suas consequências para a elaboração e implementação de políticas de desenvolvimento territorial e cultural, em especial no caso da pesquisa que ora desenvolvemos em diferentes bairros e cidades de três territórios de identidade do Estado da Bahia, já analisados em pesquisas anteriores: Metropolitano de Salvador, de Vitória da Conquista e do Portal do Sertão.

\footnotetext{
8“O bairro Alto Maron está vivenciando este novo perfil comercial. Com cerca de 420 estabelecimentos comerciais, o bairro tem o comércio bastante diversificado e tem atraído empreendedores de vários ramos" (http:/www.cdlvca.com/v1/2013/02/08/o-potencial-do-comerciodo-alto-maron/).
} 


\section{Campos da produção e do consumo}

Segundo Bourdieu (2007 [1979]), o campo é um recorte da estrutura social total, com interesses, linguagens e representações específicas. Cada campo tem uma hierarquia de classes e frações de classe, de "dominantes e dominados". Mas, para um indivíduo ou grupo de indivíduos, se posicionar em um campo não significa necessariamente anular outro campo ou se colocar na posição de dominante. Os campos possuem dinâmicas próprias, estabelecendo uma dialética entre macro e microcosmos - mais ou menos autônomos, mas atrelados à dinâmica da estrutura macro.

Deve-se admitir, nesse contexto, a existência de conflitos entre os campos (envolvendo classes e frações de classe posicionadas em cada campo). Por exemplo: campo científico versus campo religioso, campo religioso versus campo político etc. Há que se discutir também a autonomia relativa dos campos, mas isso não significa necessariamente isolamento ou exclusividade, já que, como indivíduos, nos posicionamos em muitos campos diferentes. A autonomia dos campos se traduz em mecanismos que o microcosmo aciona para existir e resistir às determinações externas. Em suma, o campo não é somente de diálogo, mas, sobretudo, de disputa, de conflito, de trajetórias ascendentes e descendentes - é um microcosmo da estrutura social e, como ela, conflituoso, disputado e desigual.

Pensando-se nos termos de Bourdieu em matéria de bens culturais e outros bens/serviços, há um ajuste entre oferta e demanda que não é simplesmente o resultado de uma imposição que a produção exerceria sobre o consumo, muito menos "o efeito de uma busca consciente mediante a qual ela antecipa as necessidades dos consumidores, mas o resultado da orquestração objetiva de duas lógicas relativamente independentes, (...) a dos campos de produção e do campo do consumo" (BOURDIEU, 2007 [1979], p. 215). Sob esta ótica, estabelece-se uma correspondência entre bens oferecidos por um determinado campo de produção e o campo do consumo, ou melhor, os gostos socialmente produzidos: "o acordo que se estabelece, assim, objetivamente entre classes de produtos e classes de consumidores só se realiza no consumo por intermédio dessa espécie de senso da homologia entre bens e grupos" (BOURDIEU, 2007 [1979], p. 217). Desse modo,

No caso da produção dos bens culturais, (...), a relação entre oferta e demanda reveste uma forma particular na medida em que a oferta exerce sempre um efeito de imposição simbólica: um produto cultural (...) é um gosto constituído, um gosto que foi levado da imprecisa semiexistência da experiência vivida para o semiformulado ou informulado (...) para a plena realidade 
do produto-acabado, por um trabalho de objetivação (BOURDIEU, 2007 [1979], p. 216).

Importante para as pesquisas que estamos desenvolvendo é a ideia de que membros de uma classe ou fração de classe vão construir nos bairros populares das cidades e regiões analisadas trajetórias como produtores/empreendedores (inclusive de bens culturais), por um lado, e, como consumidores, por outro lado, em função de sua posição na hierarquia dos campos da produção e do consumo "os produtores são levados pela lógica da concorrência com os outros produtores e pelos interesses específicos associados à sua posição no campo da produção (...) a produzir produtos distintos que encontram os interesses culturais diferentes que os consumidores devem à sua condição e à sua posição de classe" (BOURDIEU, 2007 [1979], p. 217).

Observe-se que classe social é aqui compreendida - a partir do pensamento de Bourdieu - como um conceito relacional, classe social como condição e posição, cuja operacionalização apresenta também repercussões e implicações espaciais. A discussão proposta ajuda a revelar e esclarecer, por outro lado, transformações profundas no mundo do trabalho, com consequências evidentes nos processos de apropriação do espaço na cidade contemporânea, transformações estas que enfatizam a qualificação como distinção, com profissões mais valorizadas que outras e a consciência de classe se construindo a partir do consumo (do/no espaço).

$\mathrm{O}$ conceito de classe social que embasa esta pesquisa remete, portanto, a uma noção de capital que é incorporado pelos indivíduos e grupos sob a forma de capital cultural, capital econômico e capital social: o primeiro como a soma das qualificações intelectuais produzidas pelo sistema escolar ou transmitidas pelas famílias/comunidades, o segundo como a totalidade de recursos patrimoniais e de renda e o terceiro como as relações socialmente úteis (contatos, amizades etc.) que podem ser acionadas por indivíduos e grupos em suas trajetórias nos diferentes campos da estrutura social total.

\section{Trajetória e cotidiano}

Como universos de intermediação entre o macro e o micro e sob relativa autonomia, os campos permitem uma aproximação/articulação teóricometodológica com o conceito de cotidiano. O cotidiano é categoria-chave para revelar "maneiras de fazer" que vão criar "um jogo mediante a estratificação de funcionamentos diferentes e interferentes", "um espaço de jogo para maneiras de utilizar a ordem imposta do lugar e da língua" (CERTEAU, 1996, p. 92-93). As práticas cotidianas nos campos da produção e do consumo nos bairros populares da 
cidade contemporânea podem, portanto, ser analisadas a partir do binômio produção-consumo ou de seu equivalente geral, o binômio escritura-leitura (CERTEAU, 1996, p. 49): “A leitura introduz (...) uma arte que não é passividade. (...) os procedimentos do consumo contemporâneo parecem constituir uma arte sutil de 'locatários' bastante sensatos para insinuar as suas mil diferenças no texto que tem força de lei” (CERTEAU, 1996, p. 50). Assim,

depois dos trabalhos, muitos deles notáveis, que analisaram os 'bens culturais', o sistema de sua produção, o mapa de sua distribuição e a distribuição dos consumidores nesse mapa, parece possível considerar esses bens não apenas como dados a partir dos quais se pode estabelecer os quadros estatísticos de sua circulação ou constatar os funcionamentos econômicos de sua difusão, mas também como o repertório com o qual os usuários procedem a operações próprias (CERTEAU, 1996, p. 93).

Pode-se complementar as afirmações de Certeau afirmando, a partir de Bourdieu, que as maneiras legítimas de "praticar", "usar", "consumir" são objeto de conflitos e acordos expressos no cotidiano que, por sua vez, traduzem a dinâmica e a lógica específica de cada campo, guardando relação com as trajetórias de indivíduos e grupos de produtores e consumidores na estrutura social. A noção de trajetória impede a definição da posição de indivíduos ou grupos na estrutura social de um ponto de vista estático. A trajetória de indivíduos e grupos remete sempre a posições sociais relativas numa dada estrutura ou num dado campo, bem como em um dado momento. Dessa maneira,

O ponto da trajetória, que um corte sincrônico apreende, contém sempre o sentido do trajeto social. Logo, sob pena de deixar escapar tudo o que define concretamente a experiência da posição como etapa de uma ascensão ou de um descenso, como promoção ou regressão, é necessário caracterizar cada ponto pelo diferencial da função que exprime a curva, isto é, por toda a curva. Em consequência, podemos distinguir propriedades ligadas à posição definida sincronicamente e propriedades ligadas ao futuro da posição (BOURDIEU, 2003, p. 7-8).

A produção e o consumo nas centralidades de comércio e serviços nos bairros populares devem, portanto, ser problematizados em suas dimensões materiais e imateriais já que dependem, em grande parte, do domínio de um repertório (CERTEAU, 1996) ou da disponibilidade de um "capital escolar ou cultural" 
(BOURDIEU, 2007 [1979]), o que, em última instância, vai diferenciar as trajetórias de indivíduos e grupos/classes e frações de classe nos campos e estruturas sociais específicos. Na análise aqui pretendida, a noção de repertório diz respeito, especificamente, "às práticas do espaço, às maneiras de frequentar um lugar", o reconhecimento de que há um léxico que fundamenta essas práticas como operações próprias de grupos e classes sociais específicos (CERTEAU, 1996, p. 50 e 93).

O conceito de cotidiano permite a elaboração de uma Geografia Humana dos espaços vividos, superando a visão estritamente econômica na análise das trajetórias dos diferentes indivíduos e grupos nos campos da produção e do consumo no recorte aqui proposto: bairros populares de diferentes cidades e regiões do Estado da Bahia. Pensar uma Geografia assim requer também o reestabelecimento da dialética entre espaços diferenciais e espaços homogêneos, visto que a planificação do espaço objetiva tornar todos os lugares, regiões e paisagens homólogos, "distintos tão somente por sua distância. Objetivo mensurável, o espaço só é representado em função de critérios produtivistas", segundo Lefebvre (2004, p. 117-118). A matematização do espaço, sua dominação, se traduz por "cálculos de otimização" que, por fim, vão regular os processos hegemônicos de produção espacial na contemporaneidade.

\section{Os primeiros resultados das pesquisas}

Os bairros Tomba, em Feira de Santana, e Paripe, em Salvador, foram selecionados para os primeiros levantamentos de campo iniciados em 2014, a partir dos seguintes critérios: a classificação pelo SEBRAE de bairro empreendedor, a densidade de comércio e serviços e de empreendedores, a diversidade dos estabelecimentos comerciais e de serviços, a densidade populacional e a presença de equipamentos culturais ${ }^{9}$.

Definidos os primeiros estudos de caso, foram catalogados e mapeados todos os estabelecimentos comerciais e de serviços localizados nos bairros populares escolhidos para os estudos. Foram também elaborados dois modelos de questionário para serem aplicados aos consumidores e empreendedores, visando delinear seu perfil ${ }^{10}$ a partir de amostragem não probabilística, por saturação (o

\footnotetext{
${ }^{9}$ Os dados relativos aos equipamentos culturais estão sendo levantados nos dois bairros e não serão discutidos neste artigo.

${ }^{10} \mathrm{Com}$ o questionário aplicado junto aos consumidores buscou-se levantar as seguintes informações: bairro de residência do consumidor, idade, gênero, com qual modal de transporte se desloca até o núcleo central acessado, motivo pelo qual utiliza o comércio e os serviços de determinado núcleo,
} 
tamanho da amostra é definido quando as respostas se tornam redundantes). ${ }^{11} \mathrm{~A}$ aplicação de questionários foi realizada nos núcleos comerciais e de serviços mais significativos em ambos os bairros - nos locais de maior concentração e fluxo de consumidores e empreendedores. A sistematização dos dados foi realizada na medida em que iam se efetuando os trabalhos de campo ${ }^{12}$, com a elaboração de tabelas-síntese, algumas apresentadas e discutidas neste artigo.

\section{O bairro Tomba}

Conforme os dados coletados em campo, o núcleo comercial e de serviços no Tomba recebe mais consumidores do próprio bairro, 73 residem em outros bairros, dois em distritos do próprio município e 11 em municípios próximos - como Conceição de Feira, São Gonçalo dos Campos, Tanquinho e Ipirá. Os estabelecimentos mais procurados são supermercados, farmácias, casas lotéricas, feiras livres, correios, lojas de confecções e calçados. Na visão dos consumidores, o que influencia a procura pelo comércio e serviços no bairro são a proximidade, a facilidade de deslocamento e os preços acessíveis. Apesar de alguns alegarem que não há diferença de preço em relação ao centro da cidade, preferem comprar no Tomba pelo tempo de deslocamento e pela economia nos custos de transporte. Em geral os usuários demonstram satisfação em relação ao atendimento e à diversidade de comércios e serviços oferecidos, entretanto, os que classificaram a qualidade do

quantas vezes frequenta o núcleo acessado, como avalia a qualidade do comércio e dos serviços, escolaridade, renda per capita mensal e situação de ocupação no mercado de trabalho. Questionamos também sobre os equipamentos culturais frequentados pelos consumidores, bem como o conhecimento desses consumidores em relação às políticas públicas de acesso a cultura. A aplicação dos questionários junto aos empreendedores buscou revelar, para os estabelecimentos amostrados, o tipo de atividade, o capital nele envolvido, a abrangência de atuação, se o estabelecimento possui ou não filiais em outros bairros, se os comerciantes e prestadores de serviços são moradores dos bairros onde atuam, se possuem empregados e se estes são habitantes das áreas populares das cidades analisadas, o lucro líquido dos negócios e sua capacidade de investimento, o perfil dos consumidores, se atraem demanda de outros bairros da cidade, se têm acesso a crédito, se recebem capacitação de organizações como o SEBRAE, o nível de escolaridade dos comerciantes, prestadores de serviços e consumidores etc.

${ }^{11}$ No bairro Tomba, em Feira de Santana, foram aplicados 240 questionários com os consumidores e 18 com os empreendedores; no bairro de Paripe em Salvador, 209 questionários com os consumidores e 17 com os empreendedores.

${ }^{12}$ Os levantamentos realizados em Feira de Santana e Salvador contaram com a colaboração de Mateus Barbosa Santos da Silva e Renata Oliveira Silva, estudantes de graduação em Geografia da UFBA e bolsistas de Iniciação Científica do CNPq e da FAPESB, respectivamente. 
comércio como regular, ruim e péssima demonstraram preocupação com as condições higiênicas dos alimentos comercializados na Praça Macário Barreto e afirmaram que o esgotamento sanitário é precário no bairro, reivindicando uma melhoria em sua infraestrutura.

Considerando a renda mensal per capita dos consumidores, apenas $14,58 \%$ recebem acima de dois salários mínimos (R\$ 1.448,00). A partir destes dados, é possível observar a concentração na classe de consumidores sem rendimento mensal, um grupo de 71 pessoas composto majoritariamente de mulheres. Quanto à escolaridade, 60 pessoas estão cursando e 32 concluíram o ensino fundamental e não prosseguiram com os estudos; há também uma quantidade expressiva de usuários que já concluíram o ensino médio. Fica evidente que não há uma continuidade dos estudos no nível superior, pois são apenas 10 graduados e 16 que estão cursando ou interromperam sua graduação (ver Tabelas 1 e 2).

Os usuários de comércios e serviços do bairro Tomba, em sua maioria, estão empregados e realizando diversas funções como balconista, contador, pedreiro, serviços gerais, vendedor, vigilante, teleoperador, entre outras. E $37,11 \%$ do total de empregados por nós questionados estão excluídos da legislação social e trabalhista. Por outro lado, 41 usuários do comércio e dos serviços do bairro obtêm sua renda através de trabalho independente como artesão, padeiro, cabelereiro, entre outros. 55 consumidores se declararam desempregados, sendo que 31 destes dedicam-se exclusivamente ao trabalho doméstico. Isto revela que a realização de afazeres domésticos é considerada como inatividade econômica pelos próprios questionados.

\begin{tabular}{|c|c|c|c|c|c|}
\hline \multirow{2}{*}{$\begin{array}{l}\text { Renda per } \\
\text { capita em } \\
\text { salário } \\
\text { mínimo }\end{array}$} & \multicolumn{2}{|c|}{ Mulheres } & \multicolumn{2}{|c|}{ Homens } & \multirow[b]{2}{*}{ Total } \\
\hline & $\begin{array}{c}\text { Residentes } \\
\text { no Bairro } \\
\text { Tomba }\end{array}$ & $\begin{array}{c}\text { Residentes } \\
\text { em outras } \\
\text { Localidades }\end{array}$ & $\begin{array}{c}\text { Residentes } \\
\text { no Bairro } \\
\text { Tomba }\end{array}$ & $\begin{array}{c}\text { Residentes } \\
\text { em outras } \\
\text { Localidades }\end{array}$ & \\
\hline $\begin{array}{l}\text { Não } \\
\text { declarado }\end{array}$ & 6 & 0 & 5 & 1 & 12 \\
\hline Sem Renda & 51 & 11 & 8 & 1 & 71 \\
\hline Até $1 / 2$ s.m & 10 & 4 & 0 & 0 & 14 \\
\hline $\begin{array}{l}\text { De } 1 / 2 \text { a } 1 \\
\text { s.m }\end{array}$ & 22 & 17 & 4 & 4 & 47 \\
\hline De 1 a 2 s.m & 23 & 9 & 18 & 11 & 61 \\
\hline De 2 a 3 s.m & 4 & 1 & 10 & 6 & 21 \\
\hline De 3 a 5 s.m & 0 & 3 & 4 & 4 & 11 \\
\hline de 5 a 10 s.m & 0 & 0 & 2 & 1 & 3 \\
\hline Total & 116 & 45 & 51 & 28 & 240 \\
\hline
\end{tabular}

Tabela 1: Classe de rendimento mensal per capita dos consumidores por sexo e local de residência - Bairro Tomba.

Fonte: Trabalho de Campo, 2014.

Elaboração Mateus Barbosa Santos da Silva. 


\begin{tabular}{|c|c|c|c|c|c|}
\hline \multirow[b]{2}{*}{ Escolaridade } & \multicolumn{2}{|l|}{ Mulheres } & \multicolumn{2}{|l|}{ Homens } & \multirow[b]{2}{*}{ Total } \\
\hline & $\begin{array}{l}\text { Residentes } \\
\text { no Bairro } \\
\text { Tomba }\end{array}$ & $\begin{array}{l}\text { Residentes } \\
\text { em outras } \\
\text { Localidades }\end{array}$ & $\begin{array}{l}\text { Residentes } \\
\text { no Bairro } \\
\text { Tomba }\end{array}$ & $\begin{array}{l}\text { Residentes } \\
\text { em outras } \\
\text { Localidades }\end{array}$ & \\
\hline $\begin{array}{l}\text { Nunca } \\
\text { estudou }\end{array}$ & 3 & 0 & 1 & 0 & 4 \\
\hline $\begin{array}{l}\text { Fundamental } \\
\text { Incompleto }\end{array}$ & 31 & 10 & 11 & 8 & 60 \\
\hline $\begin{array}{l}\text { Fundamental } \\
\text { Completo }\end{array}$ & 14 & 5 & 10 & 3 & 32 \\
\hline $\begin{array}{l}\text { Médio } \\
\text { Incompleto }\end{array}$ & 21 & 6 & 11 & 2 & 40 \\
\hline $\begin{array}{l}\text { Médio } \\
\text { Completo }\end{array}$ & 37 & 16 & 12 & 13 & 78 \\
\hline $\begin{array}{l}\text { Superior } \\
\text { Incompleto }\end{array}$ & 7 & 4 & 5 & 0 & 16 \\
\hline $\begin{array}{l}\text { Superior } \\
\text { Completo }\end{array}$ & 3 & 4 & 1 & 2 & 10 \\
\hline Total & 116 & 45 & 51 & 28 & 240 \\
\hline
\end{tabular}

Tabela 2: Nível de Escolaridade dos consumidores por sexo e local de residência - Bairro Tomba.

Fonte: Trabalho de Campo, 2014.

Elaboração Mateus Barbosa Santos da Silva.

A classificação dos empreendimentos para comércios e serviços utilizada em nossas pesquisas de campo tem como base a metodologia desenvolvida pelo SEBRAE/DIEESE (2013) em conjunto com a Lei Complementar $n^{\circ} 128$, de 19 de dezembro de 2008 (BRASIL, 2008). O SEBRAE classifica as empresas, a partir da quantidade de empregados, definindo-as em quatro categorias: micro (até 9), pequena (de 10 a 49), média (de 50 a 99) e grande empresa (100 ou mais) e a legislação federal institui a figura do microempreendedor individual (MEI), aquele que possui receita bruta anual de até $\mathrm{R} \$ 36.000,00$. De acordo com os 18 questionários aplicados com os empreendedores, existem 4 MEI's, 12 microempresas e 2 pequenas empresas (Tabela 3). Considerando-se os locais de residência dos empreendedores, 11 são moradores do Tomba, os demais residem em outros bairros de Feira de Santana (Tabela 4). Para desenvolver suas atividades, seis empreendedores optaram por constituir uma sociedade, em geral de caráter familiar, pois os sócios possuem algum grau de parentesco com o empreendedor. 


\begin{tabular}{lc}
\hline Classificação dos empreendimentos & Frequência \\
\hline Microempreendedor Individual & 4 \\
Microempresa & 12 \\
Pequena Empresa & 2 \\
\hline Tabela 3: Classe de empreendimentos de acordo com a metodologia empregada pelo SEBRAE \\
e a legislação federal - Bairro Tomba \\
Fonte: Trabalho de Campo, 2014. \\
Elaboração Mateus Barbosa Santos da Silva. \\
\\
\hline Local de Residência \\
\hline Tomba \\
Serraria Brasil & \\
Fraternidade & 11 \\
Centro & 1 \\
Jomafa & 1 \\
Brasília & 1 \\
Feira VII & 1 \\
George Américo & 1 \\
Total de Residentes no Tomba & 1 \\
Total de Residentes em outros Bairros & 1 \\
\hline
\end{tabular}

Tabela 4: Local de residência dos empreendedores do bairro Tomba.

Fonte: Trabalho de campo, 2014.

Elaboração: Mateus Barbosa Santos da Silva.

De acordo com os dados levantados em relação aos MEI's, três desenvolvem suas atividades comerciais e de serviços no bairro há mais de cinco anos e apenas um atua entre três e cinco anos. Destes, apenas um necessita pagar aluguel para realizar seus negócios, os estabelecimentos restantes são de caráter próprio, dois de natureza familiar e um de único dono. Entre os MEI's foram encontrados os seguintes empreendimentos: oficina de motos, comercialização de celulares, acessórios para celulares e lanchonete; venda de variedades e acessórios para cabelo; venda de variedades e reparo de relógios.

No tocante às microempresas, oito já estão no ramo há mais de cinco anos, destas uma decidiu não declarar a condição de propriedade do empreendimento, cinco alugam pontos empresariais e duas são próprias com único dono. Apenas uma atua entre três e cinco anos, sendo que o local do negócio é alugado. Por fim, três microempresas atuam entre um e três anos e todas fazem locação de pontos empresariais para a realização de suas atividades. Entre as microempresas, os tipos de negócios levantados que são mais frequentes foram: armarinho; papelaria; brinquedos e artigos para o lar; artigos e ração para animais; assistência para computadores e acessórios para celulares; embalagens e bomboniere; material de 
construção; mercadinho e armazém; moda íntima; oficina de bicicletas; confecção de cama, mesa e banho; roupas e calçados.

No universo das pequenas empresas, em apenas duas o local do empreendimento é próprio e de único dono, apesar de uma estar há mais de cinco anos e a outra menos de seis meses em atividade. A empresa que atua há mais tempo tem suas atividades voltadas à venda de materiais de construção e a mais recente é filial de uma empresa do ramo de móveis, eletrodomésticos e confecções de cama, mesa e banho - instalada no bairro há menos de seis meses.

\section{O bairro Paripe}

Há atualmente em Paripe três núcleos centrais. Eles apresentam uma grande diversidade quanto ao tipo de comércio e serviços, se mostrando também com algum grau de especialização. As atividades mais presentes são a venda de confecções (roupas, calçados) e alimentos, mas pode-se encontrar também pet shops, gráficas, estabelecimentos de consertos de móveis, entre outras.

O primeiro núcleo se localiza no final da Avenida Afrânio Peixoto (conhecida também por Suburbana), onde está localizado o Centro de Abastecimento de Paripe, que agrega vários tipos de estabelecimentos comerciais, como os de confecção e alimentos, e o de serviços como restaurantes e lotéricas. Neste primeiro núcleo, além do Centro de Abastecimento, encontram-se também lojas de confecções, calçados, móveis, eletrodomésticos, uma agência bancária do Banco Itaú, supermercados e lojas de eletrodomésticos de grande porte como as Casas Bahia. É também nesta avenida que está localizada a última estação do sistema ferroviário de Salvador, que liga o bairro Calçada ao subúrbio.

Já o segundo núcleo central considerado neste estudo é aquele da Rua Eduardo Dotto, onde está localizada a Praça João Martins e se encontram lojas de confecções, supermercados - como o da Rede Mix - e a loja de eletrodomésticos Magazine Luiza. O que difere este núcleo do primeiro é que há uma grande concentração de estabelecimentos do ramo alimentício, como bares, pizzarias, lanchonetes e restaurantes.

Há ainda o terceiro núcleo central, localizado na Rua Almirante Tamandaré. Este tem uma concentração menor de estabelecimentos comerciais se comparado aos dois primeiros, porém, é nesta rua onde se encontra um dos finais de linha do transporte coletivo rodoviário do bairro. Há um grande fluxo de pessoas por conta dos ônibus, o que confere alguma importância aos estabelecimentos comerciais e de serviços ali localizados - escolas, padarias, restaurantes, salões de beleza e barbearia - que atendem à demanda dos moradores da própria rua e proximidades. 
A presente pesquisa baseou-se nos levantamentos de Souza (2007, p. 79) que considerava também a existência em Paripe de três núcleos centrais, porém com a presença de outra rua - a Rua Iriguaçu. Neste estudo, não consideramos esta rua como um núcleo central, pois atualmente as atividades comerciais ali localizadas são menos consolidadas se comparadas àquelas dos três núcleos apresentados anteriormente. Verificou-se que o primeiro núcleo (Av. Afrânio Peixoto) concentra o maior número de consumidores, seguido pelo núcleo dois (Rua Eduardo Dotto) e, por último, com um movimento menor de consumidores, o núcleo três (Rua Almirante Tamandaré). ${ }^{13}$

Analisando-se os resultados, verifica-se que a maioria dos consumidores participantes da pesquisa é composta por moradores do bairro; também é possível constatarmos que os moradores de outras localidades não se restringem aos bairros próximos, como é o caso dos bairros da Caixa D'água e da Liberdade (ver Tabela 5), relativamente distantes do bairro de Paripe. Observou-se ainda que o número proporcional de moradores de outros bairros em relação ao número total de consumidores diminui progressivamente do núcleo um ao núcleo três. Em relação à ocupação dos consumidores dos três núcleos estudados (ver Tabela 6), 109, ou seja, mais da metade dos consumidores questionados, estão empregados.

A Tabela 7 apresenta informações cruzadas sobre a renda mensal e a escolaridade dos consumidores, donde se vê que a maioria possui o ensino médio completo. Já as pessoas que não possuem renda aparecem em número maior (48), porque nesta classificação encontram-se, além dos desempregados, os estudantes e os aposentados. A segunda classe de renda mais mencionada pelos consumidores (45) é aquela entre um e dois salários mínimos.

\footnotetext{
${ }^{13}$ Por conta dessa hierarquização, referente apenas à presença de consumidores, foram atribuídos tais números indicadores para cada núcleo: núcleo 1, núcleo 2 e núcleo 3 . Ainda por conta da diferença na quantidade de consumidores presentes em cada núcleo, o número de questionários aplicados em cada um deles também foi diferente: 105 questionários no núcleo 1, 52 questionários no núcleo 2 e 52 no núcleo 3.
} 


\begin{tabular}{|c|c|}
\hline Bairro de Residência (total dos núcleos) & Frequência \\
\hline Paripe & 146 \\
\hline 7 de Abril & 1 \\
\hline Aratu & 1 \\
\hline Arraial do Retiro & 1 \\
\hline Caixa D'água & 1 \\
\hline Cajazeiras & 1 \\
\hline Faz. Coutos/Coutos & 24 \\
\hline Ilha Amarela & 1 \\
\hline Ilha de Maré & 2 \\
\hline Ilha de São João & 1 \\
\hline Jardim Valéria & 2 \\
\hline Liberdade & 1 \\
\hline Mapele & 1 \\
\hline Massaranduba & 1 \\
\hline Mirantes de Periperi & 1 \\
\hline Narandiba & 1 \\
\hline Periperi & 9 \\
\hline Plataforma & 1 \\
\hline Praia Grande & 1 \\
\hline Rio Sena & 1 \\
\hline São Cristovão & 1 \\
\hline São João do Cabrito & 1 \\
\hline São T. de Paripe & 4 \\
\hline Susuarana Nova & 1 \\
\hline Teresinha & 1 \\
\hline Valéria & 1 \\
\hline Vista Alegre & 2 \\
\hline Total Geral & 209 \\
\hline Total de Residentes de outras localidades & 03 \\
\hline
\end{tabular}

Tabela 5: Local de residência dos consumidores (total dos núcleos) - Bairro Paripe Fonte: Trabalho de Campo, 2014.

Elaboração: Renata Oliveira Silva. 


\begin{tabular}{|c|c|}
\hline $\begin{array}{c}\text { Situação de ocupação/trabalho dos } \\
\text { consumidores }\end{array}$ & Frequência \\
\hline Empregados (as) & 109 \\
\hline Desempregados (as) & 59 \\
\hline Estudantes & 11 \\
\hline Aposentados (as)/ Pensionistas & 8 \\
\hline Autônomos & 22 \\
\hline Total Geral & 209 \\
\hline
\end{tabular}

Tabela 6: Situação de ocupação/trabalho dos consumidores (total dos núcleos) - Bairro Paripe. Fonte: Trabalho de Campo, 2014.

Elaboração: Renata Oliveira Silva.

\begin{tabular}{|l|c|c|c|c|c|c|c|c|c|}
\hline Renda Mensal & Nunca Estudou & $\begin{array}{l}\text { Fundamental } \\
\text { Incompleto }\end{array}$ & $\begin{array}{c}\text { Fundamental } \\
\text { Completo }\end{array}$ & $\begin{array}{c}\text { Médio } \\
\text { Incompleto }\end{array}$ & $\begin{array}{c}\text { Médio } \\
\text { Completo }\end{array}$ & $\begin{array}{c}\text { Superior } \\
\text { Incompleto }\end{array}$ & $\begin{array}{c}\text { Superior } \\
\text { Completo }\end{array}$ & $\begin{array}{c}\text { Pós- } \\
\text { Graduação }\end{array}$ & Total \\
\hline $\begin{array}{l}\text { Não } \\
\text { Declarado }\end{array}$ & 0 & 4 & 2 & 9 & 4 & 0 & 1 & 0 & 20 \\
\hline Sem Renda & 2 & 9 & 5 & 14 & 16 & 2 & 0 & 0 & 48 \\
\hline $\begin{array}{l}\text { Até 1/2 } \\
\text { salário } \\
\text { mínimo }\end{array}$ & 1 & 3 & 3 & 8 & 14 & 0 & 0 & 0 & 29 \\
\hline $\begin{array}{l}\text { De 1/2 a 1 } \\
\text { salário } \\
\text { mínimo }\end{array}$ & 1 & 8 & 9 & 3 & 10 & 0 & 0 & 0 & 31 \\
\hline $\begin{array}{l}\text { De 1 a } \\
\text { salários } \\
\text { mínimos }\end{array}$ & 0 & 4 & 2 & 7 & 24 & 8 & 0 & 0 & 45 \\
\hline $\begin{array}{l}\text { De 2 a 3 } \\
\text { salários } \\
\text { mínimos }\end{array}$ & 0 & 0 & 0 & 1 & 16 & 6 & 1 & 2 & 26 \\
\hline $\begin{array}{l}\text { De 3 a 5 } \\
\text { salários } \\
\text { mínimos }\end{array}$ & 0 & 2 & 0 & 0 & 6 & 1 & 0 & 1 & 10 \\
\hline $\begin{array}{l}\text { De 5 a 10 } \\
\text { salários } \\
\text { mínimos }\end{array}$ & 0 & 0 & 0 & 0 & 0 & 0 & 0 & 0 & 0 \\
\hline Total & 4 & 30 & 21 & 42 & 90 & 17 & 2 & 3 & 209 \\
\hline
\end{tabular}

Tabela 7: Relação entre classe de renda per capita mensal e escolaridade dos consumidores (total dos núcleos) - Bairro Paripe.

Fonte: Trabalho de Campo, 2014.

Elaboração: Renata Oliveira Silva. 
Do total de 17 empreendedores questionados, nove residem em Paripe e oito em outros bairros, como Águas Claras, Stela Maris, Mapele e Praia Grande. Assim como os consumidores, os empreendedores também possuem em sua maioria o Ensino Médio completo (Tabela 8). A maioria dos estabelecimentos pesquisados trabalha com estoque, conta com fornecedores fixos e possui até nove funcionários (cinco não possuem nenhum). Uma das dificuldades da pesquisa foi o fato de que muitos empreendedores não declararam a receita líquida do empreendimentooupor não saberem os valores exatos, já que muitos contratam serviço de contabilidade, ou por não se sentirem confortáveis para revelar o montante. A menor renda declarada foi de $\mathrm{R} \$ 1.200$ mensais e a maior renda declarada, de $\mathrm{R} \$ 10$ mil mensais.

\begin{tabular}{|c|c|}
\hline Grau de Escolaridade dos Empreendedores \\
\hline Escolaridade & Número de Ocorrências \\
\hline Não declarado & 1 \\
\hline Nunca estudou & 0 \\
\hline Fundamental Incompleto & 1 \\
\hline Fundamental Completo & 2 \\
\hline Médio Incompleto & 3 \\
\hline Médio Completo & 7 \\
\hline Curso Técnico & 0 \\
\hline Superior Incompleto & 2 \\
\hline Superior Completo & 1 \\
\hline Total & 17 \\
\hline
\end{tabular}

Tabela 8: Escolaridade dos empreendedores (total dos núcleos) - Bairro Paripe.

Fonte: Trabalho de Campo, 2014.

Elaboração: Renata Oliveira Silva.

As entrevistas: capital econômico, capital cultural e capital social dos empreendedores

Encerrados os levantamentos mais exaustivos dos núcleos centrais dos dois bairros, das características dos empreendimentos e do perfil de consumidores e empreendedores, iniciou-se em 2015 as entrevistas de cunho qualitativo com os empreendedores amostrados entre aqueles que responderam aos questionários na primeira etapa da pesquisa. Com essas entrevistas, os empreendedores estão sendo caracterizados quanto à sua posição e sua condição na estrutura social, nos moldes como propõe Bourdieu (2007 [1979]), enfatizando suas trajetórias e seu capital 
(social, cultural e econômico), de modo a explicitar as classes e frações de classe envolvidas nos processos de complexificação/diversificação das centralidades de comércio e de serviços dos bairros populares nas cidades e territórios analisados.

Com essas entrevistas buscou-se também caracterizar os imaginários-motores ${ }^{14}$ dos diferentes agentes e grupos dos espaços de conceituação considerados (bairros, cidades, regiões/territórios). Supõe-se também que os processos analisados aqui apontam para a constante renovação dos imaginários-motores (ENRIQUEZ, 1996) dos diferentes agentes e grupos, das diversas classes e frações de classe, imaginários estes que consolidam limites espaciais e referenciais coletivos, articulando as diferentes percepções e experiências em uma trama de relações socioespaciais que se manifestam nos diferentes espaços de conceituação abordados (bairros, cidades, regiões/territórios), caracterizando experiências compartilhadas de territorialização do espaço urbano-regional, através da consolidação/diversificação das centralidades de comércio e serviços nos bairros populares das cidades abordadas.

As primeiras quatro entrevistas realizadas (duas no Tomba, duas em Paripe ${ }^{15}$ ) serviram para balizar e ajustar o roteiro de perguntas, permitindo ao mesmo tempo extrair algumas observações iniciais em relação aos objetivos de nossas pesquisas, em especial à caracterização do perfil, da posição/ condição social e da trajetória dos empreendedores entrevistados. Donde se destaca que:

- todos os entrevistados expressam a vontade de expandir seus negócios, diversificando suas atividades ou abrindo filiais em outros bairros ou no centro das cidades ou, ainda, em outras cidades das regiões onde atuam;

- são empreendedores que sempre atuaram no comércio e nos serviços e expandiram suas atividades a partir de empréstimos bancários ou ajuda de parentes/família, o que denota uma trajetória ascensional, nos termos de Bourdieu, na estrutura social;

- em comum, apesar de pertencerem a gerações/faixas etárias diferentes, nossos entrevistados praticamente restringem seu lazer a atividades com a família, somente uma declarou frequentar equipamentos culturais (cinema);

- os quatro entrevistados declararam também que em caso de necessidade de ajuda, se financeira, recorreriam a um banco ou à família. Também admitiram que, como

\footnotetext{
14، O imaginário-motor (...) é um imaginário dinâmico, inventivo. Sua presença permite que as pessoas envolvidas formulem projetos individuais ou coletivos, pensem nos meios a utilizar e lhes dá o gosto e o desejo de realizá-los através da transformação do mundo exterior" (ENRIQUEZ, 1996, p. 180).

${ }^{15}$ No bairro Tomba foram entrevistados um comerciante de sapatos e bolsas e uma lojista de confecções íntimas e artigos de sexshop; no bairro de Paripe, um comerciante de produtos para bebês e outra de artigos de informática.
} 
empreendedores, têm pouco tempo para os amigos, apesar de declararem ter boas relações com os outros comerciantes e prestadores de serviços nos núcleos onde atuam;

- os quatro primeiros entrevistados demonstram uma inserção continuada nos lugares onde atuam, com fortes vínculos com os bairros, cidades e regiões em que se inserem, construídos através do fortalecimento do capital social (relações de amizade, vizinhança, parentesco, socialmente "úteis") ao longo de suas trajetórias de vida, capital social que será comprometido paulatinamente com a ascensão progressiva na estrutura social;

- as trajetórias dos quatro entrevistados indicam algumas mudanças no tocante aos negócios, seja de estatuto (um feirante que virou lojista e que desde a infância comercializa sapatos e artigos de couro), seja de tipo de produtos comercializados (uma comerciante que trabalhou a vida inteira com a família com artigos de informática e em alguns momentos comercializou também materiais de construção);

- nenhum dos quatro entrevistados tem curso superior completo. Um declarou estar cursando universidade e outra afirmou que tem vontade de fazer curso superior. Um entrevistado declarou possuir apenas o ensino fundamental incompleto;

- os quatro entrevistados associam classe social a classe de renda (e aos bens materiais que possuem), de algum modo assumindo o discurso oficial da nova classe média nos bairros populares de nossas cidades;

- todos tiveram alguma dificuldade em definir o que é cultura, apenas uma entrevistada associou o termo a seu cotidiano e às manifestações da cultura popular.

As primeiras entrevistas realizadas forneceram subsídios para a continuidade das pesquisas e elementos que permitem situar as trajetórias dos empreendedores no tempo e no espaço, possibilitando também inferir que a ascensão na estrutura social dos entrevistados provoca o endividamento (foi surpreendente perceber que todos recorreriam a um empréstimo no banco em caso de dificuldades) e, ao mesmo tempo, o empobrecimento do capital social que dispõem (lazer restrito, falta de tempo para os amigos e para frequentar equipamentos culturais). O capital escolar/cultural permanece praticamente inalterado, a continuidade dos estudos na universidade dependendo de um enorme esforço pessoal daqueles que se dispõem a fazê-lo. Ou seja, são fortes os indícios de que essa ascensão social se dá mais pela inserção no consumo do que por um incremento dos anos de escolaridade ou por participação em eventos e manifestações culturais. Por outro lado, percebe-se também que esta inserção pelo consumo pode interferir na vida de relações sociais dos bairros populares analisados, com o empobrecimento do capital social de empreendedores (e consumidores) em suas trajetórias ascendentes na estrutura 
social das cidades e regiões onde atuam, com consequências, portanto, na estrutura social dos bairros como um todo.

\section{Considerações Finais}

Os resultados preliminares apresentados e discutidos neste artigo mostram que as abordagens superficiais acerca da formação de uma nova classe média nos bairros populares das cidades brasileiras devem ser evitadas, precisando-se enfrentar e aprofundar o "debate sobre a natureza e a dinâmica das mudanças econômicas e sociais" no Brasil, como propõe Pochmann (2012, p. 8). O autor não acredita na emergência de uma nova classe - muito menos de uma nova classe média no país - e propõe uma interpretação das transformações sociais dos anos 2000 sob a ótica do mercado de trabalho. Entre 2004 e 2010 houve um crescimento expressivo na geração de empregos no setor de serviços, com $95 \%$ dos novos postos de trabalho concentrados na base da pirâmide (rendimentos de até 1,5 salários mínimos) e uma maior participação do rendimento do trabalho na renda nacional (POCHMANN, 2012).

Tendo em vista a importância do emprego de baixa remuneração, que constitui a base da pirâmide distributiva do conjunto dos rendimentos do trabalho - ou seja, $47,8 \%$ do total da força de trabalho ocupada e $24,5 \%$ das remunerações do país - , cabe analisar sua evolução recente diante das transformações mais gerais da economia e da sociedade brasileira. Esse segmento social em especial não poderia estar associado ao conceito de classe média ascendente tendo em vista as peculiaridades de suas ocupações e remuneração (...). O debate a respeito da definição de classe social no capitalismo - em particular a da classe média - assume maior complexidade, para o qual se pressupõe maior profundidade e investigação (POCHMANN, 2012, p. 29-30).

Concorda-se, a partir dos resultados iniciais de nossas pesquisas, que a chamada classe $\mathrm{C}$ nos bairros populares de nossas cidades reúne "elementos tanto de uma classe trabalhadora 'pós-fordista' (...) superexplorada, sem tradição de solidariedade de classe e se acreditando empresários de si mesmos, com elementos de uma pequena burguesia (...), no sentido de empreender pequenos negócios (...)" (SOUZA, 2015). O sociólogo Jessé Souza classifica esses trabalhadores como "batalhadores brasileiros", título de um de seus livros mais recentes (SOUZA, 2010): 
A vida dos 'batalhadores' é completamente outra. Ela é marcada pela ausência dos 'privilégios de nascimento' que caracterizam as classes médias e altas. Como lhes faltam tanto o capital cultural altamente valorizado das classes médias 'verdadeiras', quanto o capital econômico das classes altas, eles compensam essa falta com extraordinário esforço pessoal, dupla jornada de trabalho e aceitação de todo tipo de super exploração da mão de obra. Essa é uma condução de vida típica das classes trabalhadoras, daí nossa hipótese de trabalho desenvolvida no livro que nega e critica o conceito de 'nova classe média' e tenta construir um conceito de 'nova classe trabalhadora', produto das novas condições da divisão de trabalho internacional e da nova dominância global do capital financeiro. Esses fatores fazem com que essa nova classe não tenha nada de 'especificamente brasileira', já que países como China, Índia e grande parte do sudeste asiático também devem boa parte de seu dinamismo atual a este mesmo fenômeno (SOUZA, 2012).

Nesse contexto, pode-se afirmar que, nos dois bairros populares analisados, tanto empreendedores como consumidores reúnem exatamente as características elencadas por Jessé Souza para a nova classe trabalhadora, um estrato "que dinamizou a economia brasileira na última década e estimulou o mercado de consumo de bens duráveis" (SOUZA, 2015). Trata-se de uma "classe muito heterogênea, com distinções regionais importantes e abrangendo desde pequenos empresários até trabalhadores superexplorados e sem direitos sociais" (SOUZA, 2015). A superexploração de que fala Souza também compromete o tempo livre dos empreendedores e consumidores alcançados por nossas pesquisas, que trabalham muitas horas por dia e, em termos de escolaridade, não conseguem em geral ascender ao ensino superior, alguns, inclusive, possuem apenas o ensino fundamental completo. As pesquisas realizadas até aqui permitem também afirmar que nos anos 2000 houve, sem dúvida, uma dinamização das centralidades de comércio e serviços nos bairros populares das cidades brasileiras. Esta dinamização resultou em uma maior complexidade/diversidade dos núcleos comerciais desses bairros, embora já se possa vislumbrar diferenças socioespaciais significativas entre as centralidades analisadas em Paripe (três núcleos centrais e maior diversidade dos produtos e serviços oferecidos) - bairro popular do território Metropolitano de Salvador - e no Tomba (apenas um núcleo central, com comércio e serviços menos diversificados) - localizado em Feira de Santana, cidade média do território do Portal do Sertão.

Com o andamento das pesquisas pretende-se aprofundar a análise das distinções regionais entre os bairros empreendedores, focando também em possíveis 
diferenças no perfil dos empreendedores e consumidores entre as cidades e regiões analisadas. Não menos importante será a atenção específica aos campos da produção e do consumo culturais, bem como ao papel das políticas de desenvolvimento territorial e cultural e seus impactos nos diferentes lugares e regiões analisados, dando prosseguimento à investigação anteriormente desenvolvida sobre a articulação de escalas geográficas nos processos de formulação/implementação e gestão de políticas territoriais e culturais. Aqui, espera-se aprofundar a análise no recorte de bairro articulado aos demais recortes/espaços de conceituação (cidade, região, território estadual), problematizando as trajetórias, táticas e estratégias dos diferentes indivíduos e grupos como empreendedores/consumidores ou, mais especificamente, como agentes e consumidores no campo da produção e do consumo culturais, e dando ênfase à dimensão espacial em seu contexto de atuação.

\section{Bibliografia}

BORGES, Clarissa. (2013) Expansão da classe C impulsiona o comércio em bairros populares. Jornal A Tarde. Salvador, 28/4/2013. pp. 1-3.

BOURDIEU, Pierre. (2007 [1979]) A Distinção - crítica social do julgamento. Porto Alegre: Zouk.

. (2003) A economia das trocas simbólicas. 5. Ed. $1^{a}$ Reimpressão. São Paulo: Perspectiva.

BRASIL. Casa Civil. (2008) Lei Complementar $n^{\circ}$ 128, de 19 de dezembro de 2008. Altera a Lei Complementar $n^{\circ} 123$, de 14 de dezembro de 2006, altera as Leis $n^{\circ} 8.212$, de 24 de julho de 1991, 8.213, de 24 de julho de 1991, 10.406, de 10 de janeiro de 2002 - Código Civil, 8.029, de 12 de abril de 1990, e dá outras providências.

Disponível em: <http://www.planalto.gov.br/ccivil_03/Leis/LCP/Lcp128.htm>. Acesso em: 19 jan. 2015.

BRASIL. Ministério da Cultura. (2014) Mais Cultura. Disponível em: <http://www.cultura.gov.br/mais-cultura>. Acessado: 18 fev. 2015.

CERTEAU, Michel de. (1996)A invenção do cotidiano. 2. Ed. Petrópolis-RJ: Vozes.

COMPANS, R. (2005) Empreendedorismo Urbano - Entre o discurso e a prática. São Paulo: Editora UNESP.

CÂMARA DE DIRIGENTES LOJISTAS DE VITÓRIA DA CONQUISTA. (2013) Crescimento do Comércio: O Potencial do Alto Maron, 8 de fevereiro de 
2013. Disponível em: <http://www.cdlvca.com/v1/2013/02/08/o-potencial-docomercio-do-alto-maron/>. Acessado em: 18 fev. 2015.

ENRIQUEZ, Eugène. (1996) Como estudar as organizações locais. In: COLÓQUIO SOBRE PODER LOCAL, 6, Salvador, 1994. Anais... Salvador: NPGA/UFBA. pp. 179-187.

HARVEY, David. (2005) A produção capitalista do espaço. São Paulo: Annablume.

LEFEBVRE, Henri. (2004) A Revolução Urbana. 2a Reimpressão. Belo Horizonte: Editora da UFMG.

POCHMANN, Marcio. (2012) Nova classe média? O trabalho na base da pirâmide social brasileira. São Paulo: Boitempo Editorial.

ROCHA, Sophia C. (2010) Programa Cultura Viva: trajetória e desafios de uma nova política cultural. In: VI ENCONTRO DE ESTUDOS MULTIDISCIPLINARES EM CULTURA. Anais do VI Encontro de Estudos Multidisciplinares em Cultura. Salvador: CULT.

SAE. Secretaria de Assuntos Estratégicos. (2012) Vozes da classe média. Caderno 02 - Desigualdade, heterogeneidade e diversidade. Brasília: SAE.

SEBRAE. Serviço Brasileiro de Apoio às Micro e Pequenas Empresas; DIEESE. Departamento Intersindical de Estatística e Estudos Socioeconômicos. (2013) Anuário do trabalho na micro e pequena empresa. Brasília, DF: SEBRAE/DIEESE.

SERPA, Angelo (org.). (2001) Fala, Periferia! Uma reflexão sobre a produção do espaço periférico metropolitano. Salvador: Editora da Universidade Federal da Bahia/Pró Reitoria de Extensão.

(org.). (2007a) Cidade Popular - Trama de Relações Sócio-Espaciais. Salvador: Editora da Universidade Federal da Bahia - EDUFBA.

. (2007b)O espaço público na cidade contemporânea. São Paulo: Contexto.

. (2011) Políticas públicas e o papel da geografia. Revista da ANPEGE, v.

7. pp. 37-47.

(org.). Territórios da Bahia: regionalização, cultura e identidade. Salvador: EDUFBA, 2015.

SOUZA, Flávia S. de. (2007) Caracterização sócio-econômica e cultural de um bairro popular em Salvador: o caso de Paripe, no subúrbio ferroviário. In: SERPA, Angelo (Org.). Cidade Popular - Trama de Relações Sócio-Espaciais. Salvador: EDUFBA. pp. 67-98.

SOUZA, Jessé. (2010) Os batalhadores brasileiros: nova classe média ou nova classe trabalhadora? Belo horizonte: Editora da UFMG. 
- (2012) Entrevista de Jessé Souza ao blog Prosa Disponível em: <http://oglobo.globo.com/blogs/prosa/posts/2012/05/12/entrevista-com-sociologojesse-souza-444686.asp>. Acessado em: 17 fev. 2015. . (2015) Ralés, batalhadores e uma nova classe média. Entrevista especial com Jessé Souza. Disponível em: $<$ http://amaivos.uol.com.br/amaivos09/noticia/noticia.asp?cod_canal=41\&cod_noti cia=16935>. Acessado em: 17 fev. 2015.

TOURINHO, Raíza. (2013) Classes em ascensão ainda preferem continuar em bairros populares. Jornal A Tarde. Salvador, 31/3/2013. p. A-6.

VALE-CULTURA FACILITA ACESSO DOS TRABALHADORES AO LAZER. (2012) Portal Brasil. Disponível em: <http://www.brasil.gov.br/sobre/cultura/iniciativas/vale-cultura>. Acessado em: acesso: 18 fev. 2015.

\section{Sites consultados}

ASN - BAHIA. (2015) Disponível em: <http://www.ba.agenciasebrae.com.br/sites/asn>.Acessado: 18 fev. 2015.

SAE. (2015) Disponível em: <http://www.sae.gov.br/site/>.Acessado: 18 fev. 2015. 